\title{
Physicochemical properties of stabilized sewage sludge admixtures by modified steel slag
}

https://doi.org/10.1515/chem-2018-0059

received December 23, 2017; accepted April 18, 2018.

Abstract: Cement stabilization is used extensively to solidify sludge. However, previous studies suggest that the organic acids in sludge can restrain the hydration processes of cementitious materials. This study presents a new binder (steel slag based materials) whose effectiveness of stabilization was investigated on sewage sludge. Several series of tests for solidified sludge were conducted including the moisture content, compressive strength, shear force, permeability, and toxicity characteristic leaching (TCLP). The result shows that the stabilization effect of physicochemical properties of stabilized sewage by $\mathrm{S}^{\star}$ (content $90 \%$ steel slag) were better than that of cement. With $20 \%$ S1, the moisture content of the sludge could be reduced to $30 \%$ at $20+1^{\circ} \mathrm{C}$ for 7 days; The compressive strength was $74.5 \mathrm{kappa}$ and the permeability coefficient was $5.03 \times 10^{-5}(\mathrm{~cm} / \mathrm{s})$; The TCLP was below the limit value. The hydration products of paste and solidified sludge at 1, 3, 14, 28, and 90 days were analyzed by XRD, SEM, and energy spectroscopy to distinguish ettringite/ iron ettringite in S1 solidified sludge. the result shows the Needle-like ettringite of S1 possess high iron content and may be Fe-Aft.

Keywords: Steel slag; Sludge; Solidification and hydration; Leaching toxicity; Ettringite/Iron ettringite.

*Corresponding author: Fei Li , Department of Environmental Science and Engineering, Zhongnan University of Economics and Law, Wuhan 430073, China; Research Center for Environment and Health, Zhongnan University of Economics and Law, Wuhan 430073, China, E-mail: lifei@zuel.edu.cn

Xi Zhu, *, Jingdong Zhang, Shengzhe Wu: Department of Environmental Science and Engineering, Zhongnan University of Economics and Law, Wuhan 430073, China

Xi Zhu, Jingdong Zhang: Research Center for Environment and Health, Zhongnan University of Economics and Law, Wuhan 430073, China

\section{Introduction}

In China, the government and markets only pay attention to sewage treatment and reject sludge treatment exposure for a long time. Thus, numerous new processes have been developed for the treatment of municipal sludge from concentrated dehydration to final disposal. However, the amount of untreated sludge accumulated over the years remains massive. This causes several issues with regard to sludge, including high water content, low strength, lack of bearing capacity and the anaerobic environment of the sludge which causes the decomposition of organic matter and the release of flammable methane that can easily lead to safety accidents [1-3].

Sludge solidified by cementitious materials for reusing is a kind of common treatment methods. Cementitious materials commonly include cement, fly ash, lime, gypsum, slag, and others [4]. The hydration process of this kind of material is often accompanied by the formation of hydration heat, and the hydration products can destroy the sludge flocculation structure, which can improve the sludge drying rate [5-7]. For example, Kim et al. used 30\% steel slag and 10\% quicklime to solidify digested sludge. The microscopic analysis proved that the formation of calcium-silicate-hydrate (C-S-H) gel changes the sludge structure [8]. Zhen et.al used 5\% and 10\% calcium aluminate gypsum curing sludge, the moisture content to $50 \%-60 \%$ after curing for $5-7$ days. Abundant water, zeolite, and $\mathrm{CaCO}_{3}$ formed in the sludge [9]. Yang et al. discovered that the addition of concentrated sludge with $2.0 \mathrm{~g} \bullet \mathrm{g}^{-1}$ DS skeleton constructs (dry solid, sludge dry basis) can reduce the moisture content of the cake to below $60 \%$, and the added cement- steel slag-fly ash sludge-based curing agent can be made of landfill cover material [10-11].

The curing agent dosage is usually larger because sewage sludge contains $500-1500 \mathrm{mg} / \mathrm{L}$ alkalinity as $\mathrm{CaCO}_{3}$, which can provide cemented benefits; however, sludge also contains 200-2000 mg/L organic acids as Humic acid, which can restrain the hydration processes of cementitious materials [12-14]. Minocha et al. [15] found 
that animal fat, hexachlorobenzene, trichloroethylene, phenol and other organic matter affect accumulation density and compressive strength of solidified sludge. Zhu et al. [16] found a limit to the effect of unconfined compressive strength and failure strain of silt solidified soil when humic acid inhibits the strength (3.62\%); beyond this limit, the strength and failure strain of solidified soil no longer changes even with increased humic acid content of silt soil. The results also show that the plasticity of solidified soil is enhanced with the increase in humic acid content. Humus exerts a restraining effect on the hydration of cement. The inhibitory effects of humus on cement hydration is mainly due to the adsorption film; when humic acid in humus comes in contact with the mineral in cement, a layer of adsorption film forms on the surface of minerals, hindering further hydration reaction. In addition, humic acid can easily combine with minerals with high alumina content yielding hydrated products such as hydrated calcium aluminate, hydrated calcium sulfoaluminate and etc. The hydrolysis of hydrated calcium aluminate crystal reduce the strength of cement stone during hydration [17]. Further research shows that $12 \mathrm{CaO} \cdot 7 \mathrm{Al}_{2} \mathrm{O}_{3}$ can enhance the effect of cement-solidified sludge because the presence of aluminate counteracted the interference from organic matters, favored the formation of crystalline phases ettringite, when the addition of $10 \%$ of $12 \mathrm{CaO} \cdot 7 \mathrm{Al}_{2} \mathrm{O}_{3}$ to cement can increase the 28-day strength of sludge to $157.2 \mathrm{kPa}$ [18].

The mineral composition of steel slag is similar to that of cement, include $\mathrm{C}_{2} \mathrm{~S}\left(2 \mathrm{CaO} \cdot \mathrm{SiO}_{2}\right), \mathrm{C}_{3} \mathrm{~S}\left(3 \mathrm{CaO} \cdot \mathrm{SiO}_{2}\right)$, $\mathrm{C}_{4} \mathrm{AF}\left(4 \mathrm{CaO} \cdot \mathrm{Al}_{2} \mathrm{O}_{3} \cdot \mathrm{Fe}_{2} \mathrm{O}_{3}\right)$ and $\mathrm{C}_{3} \mathrm{~A}\left(3 \mathrm{CaO} \cdot \mathrm{Al}_{2} \mathrm{O}_{3}\right)$, but the content of $\mathrm{C}_{2} \mathrm{~S}, \mathrm{C}_{3} \mathrm{~S}$ is lower and $\mathrm{C}_{4} \mathrm{AF}$ and $\mathrm{C}_{3} \mathrm{~A}$ is higher. $\mathrm{C}_{4} \mathrm{AF}$ and $\mathrm{C}_{3} \mathrm{~A}$ can generate ettringite [19-20]. This paper will discuss the best ratio of modified steel slag used for sludge solidification, and leaching toxicity and physicochemical properties of solidified sludge. Furthermore, the hydration property and mechanism of modified steel slag and solidified sludge were analyzed.

\section{Materials and Methods}

\subsection{Raw materials}

Dewatered sewage sludge with a moisture content of $78 \%$ and $\mathrm{pH}$ of 7.03 was obtained from a sewage treatment plant in Wuhan. The steel slag was sourced from a steel company in Wuhan, fluorgypsum was purchased from Zhonggu Company. The chemical compositions and physical characteristics of the materials after pretreatment are listed as below in Table 1 .
Table 1: Chemical and physical characteristics of the raw materials.

(a) Chemical composition of binder materials (wt. \%)

\begin{tabular}{lllllll}
\hline Sample & $\mathrm{MgO}$ & $\mathrm{Al}_{2} \mathbf{O}_{3}$ & $\mathrm{SiO}_{2}$ & $\mathrm{P}_{2} \mathbf{O}_{5}$ & $\mathrm{CaO}$ & $\mathrm{Fe}_{2} \mathbf{O}_{3}$ \\
\hline Steel slag & 6.28 & 3.59 & 15.5 & 1.45 & 49.84 & 23.34 \\
Activator & 7.977 & 15.94 & 29.94 & 0.024 & 38.65 & 1.175 \\
fluorgypsum & -- & 0.15 & 0.61 & -- & 40.62 & 0.133 \\
\hline
\end{tabular}

(b) Physical properties of binders and sludge

\begin{tabular}{llll}
\hline & $\begin{array}{l}\text { Apparent } \\
\text { density }\left(\mathrm{g} / \mathrm{cm}^{3}\right)\end{array}$ & $\begin{array}{l}\text { Specific surface } \\
\text { area }\left(\mathrm{cm}^{2} / \mathrm{g}\right)\end{array}$ & $\mathrm{pH}$ \\
\hline Steel slag & 3.31 & 494.3 & 12.69 \\
Activator & 2.91 & 231.1 & -- \\
fluorgypsum & 2.84 & 247.2 & 1.90 \\
\hline
\end{tabular}

\subsection{Moisture content}

The method for moisture content was according to $\mathrm{CJ} / \mathrm{T}$ 362-2011, and CJ/T221-2005. The dosage of steel slag is determined by the effect of reducing the water content of sludge. When sludge was modified by solidified material, the change in moisture content may be due to the addition of dry solid. To eliminate this kind of deviation, we used the actual moisture content instead of original moisture content of sludge. The following equation shows the relationship between the two kinds of moisture content:

$\mathrm{AC}=\mathrm{OC} \times \mathrm{M}$

Where AC is the actual moisture content of sludge, OC is the original moisture content of sludge, and $\mathrm{M}$ is the dosage of sludge.

\subsection{Strength test and TCLP test}

The stabilized sludge was sampled by ring knife, and then the compression strength and direct shear test was carried out after curing to the specified age. The modified sludge was pressing into the mold (internal diameter 61.8 $\mathrm{mm}$, height $20 \mathrm{~mm}$ ) after being stirred uniformly. Then modified sludge was cured at temperature of $20+1^{\circ} \mathrm{C}$ till the testing age. Compression strength and shear strength were measured according to CJ/T 249-2007 standard methods.

The concentrations in heavy metals were measured by means of toxicity characteristic leaching procedure (TCLP), which is used to examine the leaching behavior 
of heavy metals in these cement-based waste materials and described by GB16889-2008 and HJ/T 300-2007. The heavy metal was measured by atomic absorption spectrophotometer [21].

\subsection{X-ray diffraction and scanning electron microscopy}

The crystalline phases present in the solidified waste samples were characterized using $\mathrm{Cu}$-K $\alpha \mathrm{X}$-ray diffraction (XRD). XRD measurements were conducted with a D/MAXIIIR diffractometer using nickel-filtered $\mathrm{CuKa1}$ radiation (=1.5405 $\AA, 40 \mathrm{kV}$ and $30 \mathrm{~mA}$ ) from company RIGAKU of Japan. Sample cured for different days were crushed into powder by using a mortar and pestle. The powder was sieved through $150 \mu \mathrm{m}$ meshes and scanned from $5^{\circ}$ to $70^{\circ}$. The microstructures of solidified sludge were observed by scanning electron microscopy (SEM model for model JSM-5610LV, with the following basic parameters: high resolution vacuum mode, $3.0 \mathrm{~nm}$; low vacuum mode resolution, $4.0 \mathrm{~nm}$; magnification: $\times 18$ to $\times 300000$; acceleration voltage, $0.5-30 \mathrm{kV}$; and low vacuum, $1-270$ Pa.). Moreover, energy dispersive spectroscopy (EDS) was used to identify various microstructures in the solidified waste forms by determining their elemental composition. Ethical approval: The conducted research is not related to either human or animals use.

\section{Results}

\subsection{Moisture content of solidified sludge}

The three-day moisture content of the solidified sludge with different mix formulations are illustrated in Figure 1. The ratio of sludge/solidified materials was 9:1, so the actual moisture content of sludge is $70.2 \%$. ( $\mathrm{AC}=\mathrm{OC} \times$ $\mathrm{M}=78.2 \% \times 90 \%=70.2 \%$ )

As seen in the curves of the moisture content and the mix formulation of modifier in Figure 1 shows, the moisture content increased with the increase of steel slag content when fluorogypsum was added in the modifier and was higher than those with other modifiers. In general, the moisture content decreased to a lower value when $2.5 \%$ fluorogypsum was added compared with that with $5 \%$ fluorogypsum addition. The optimum formulation of the solidified material is as follows: steel slag admixture, $90 \%$; activator admixture, 10\%; and fluorogypsum, 2.5\% (we

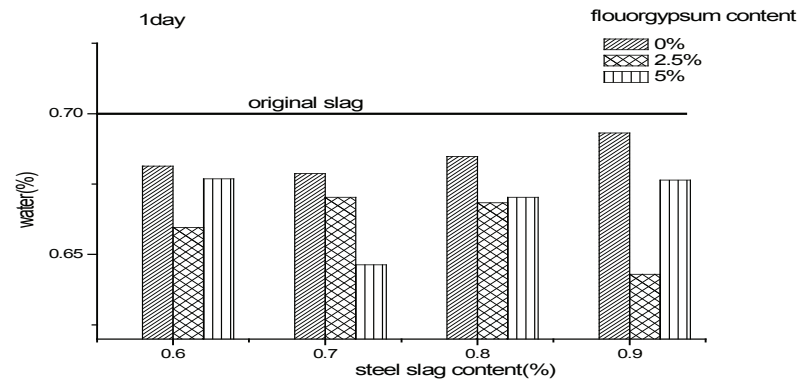

Figure 1: Moisture content change of solidified sludge (Steel slag-Activator-flouorgypsum).

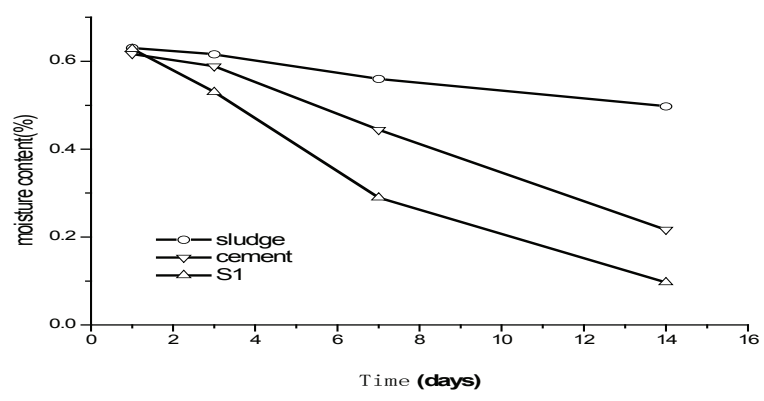

Figure 2: Moisture content change of modified sludge.

call this kind of solidified material S1 in this paper). After the addition of fluorine gypsum, slag aluminosilicates can generate ettringite. Ettringite is generated earlier than $\mathrm{C}-\mathrm{S}-\mathrm{H}$ and AFm. After curing at a temperature of $20+1^{\circ} \mathrm{C}$ for 1 day, the moisture content of the solidified sludge drops to $64 \%$ with the addition of $10 \% \mathrm{~S} 1$, and the actual moisture content of sludge is $70.2 \%$.

The variation in moisture content of solidified sludge with curing time is shown in Figure 2. The moisture content change of original sludge is not significant because the sludge floc structure possesses strong water retention properties. Only the outer layer of water was lost due to evaporation, whereas internal moisture is difficult to remove. Moisture of sludge decreased linearly with the increasing of S1 modifier, and the effect of S1 is superior to that of common cement. When the content of S1 was 20\%, the moisture content of sludge can decrease to less than $30 \%$ after curing for seven days.

\subsection{Mechanical properties of solidified sludge}

The shear force variation of sludge is shown in Figure 3. The transverse shear strength of S1 modified sludge 
(S1 20\%) was markedly higher than that of cement. Taking the 14-day shear strength as an example, under an external pressure was $50 \mathrm{MPa}$, the shear strength of S1 modified sludge was close to $80 \mathrm{MPa}$, whereas the shear strength of cement modified sludge was only 68.3 $\mathrm{MPa}$. The difference increases slightly with the increase in external force. With the extension of the modified age, the internal friction angle of the modified sludge increased, the change trend of the internal friction angle between the $\mathrm{S} 1$ and the modified sludge was similar, and the effect of S1 modified sludge was slightly better. Moreover, the cohesive force of modified sludge increased, and the S1 modified sludge showed an evident growth advantage. Numerous factors affect the sludge shear strength index, such as type, density, water content etc. The decrease of moisture content of S1 modified sludge, which is one of the causes of the change in shear strength, is lower than that of modified sludge. However, further analysis in the following microscopic analysis is required to determine whether the structure of S1 modified sludge changed, leading to a change in sludge density, particle size, and sludge structure change.

As shown in Table 2, the unconfined compressive strength of S1 modified sludge can reach $74.5 \mathrm{kPa}$, and the permeability coefficient was $5.03 \times 10^{-5}(\mathrm{~cm} / \mathrm{s})$. These results were superior to those of cement-modified sludge under the same conditions and demonstrate good water permeability. However, the change in sludge density was not evident. Physical properties of S1 solidified sludge reach the landfill map coverage standards.

\subsection{Leaching performance}

The leaching concentration of heavy metals in sludge was in the standard limits, as shown in Table 3, the leaching concentration of as is the closest to the standard limit. Heavy metals except for $\mathrm{Fe}$ are present at low contents in the modifier. Therefore, the analysis of the leaching toxicity of different modified sludge was restricted to As and Fe. Results are shown in Table 4. Compared with that of original sludge (As content $100 \mu \mathrm{g} / \mathrm{L}$ ), the As in the solidified sludge was effectively consolidated, and S1 showed the best consolidation effect $(14.58 \mu \mathrm{g} / \mathrm{L})$. The Fe element in the S1 solidified sludge is also the smallest; the As and Fe elements in S1 solidified sludge are more involved in the reaction and consolidated in the stable crystal. The great effect on sludge heavy metal steading attribute to the high alkalinity, porous structure and complexion exchanging of S1 hydration process as most of cementitious materials have [22-23].

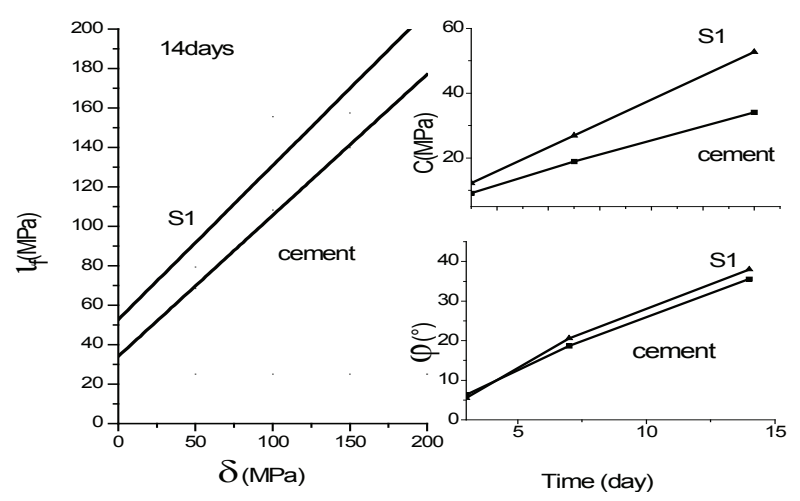

Figure 3: Shear force change of modified sludge.

Table 2: Mechanical properties of modified sludge.

\begin{tabular}{llll}
\hline Modifier & $\begin{array}{l}\text { Density } \\
\left(\mathrm{g} / \mathrm{cm}^{3}\right)\end{array}$ & $\begin{array}{l}\text { Unconfined com- } \\
\text { pressive strength } \\
(\mathrm{kPa})\end{array}$ & $\begin{array}{l}\text { Permeability coef- } \\
\text { ficient }(\mathrm{cm} / \mathrm{s})\end{array}$ \\
\hline Cement & 1.35 & 29.5 & $4.84 \times 10^{-6}$ \\
S1 & 1.33 & 74.5 & $5.03 \times 10^{-5}$ \\
\hline
\end{tabular}

Table 3: Heavy metal content of original sludge.

\begin{tabular}{|c|c|c|c|c|c|}
\hline & $\mathrm{Zn}$ & $\mathrm{Pb}$ & $\mathrm{Cr}$ & $\mathrm{Ni}$ & As \\
\hline $\begin{array}{l}\text { Total heavy metal } \\
\text { content }(\mathrm{mg} / \mathrm{kg})\end{array}$ & 950 & 101 & 495 & 40 & 29 \\
\hline $\begin{array}{l}\text { Leaching concen- } \\
\text { tration of heavy } \\
\text { metals of TCLP } \\
(\mathrm{mg} / \mathrm{L})\end{array}$ & 0.005 & 0.011 & 0.016 & 0.025 & 0.1 \\
\hline $\begin{array}{l}\text { Limit value of } \\
\text { TCLP }\end{array}$ & 100 & 0.25 & 0.15 & 0.5 & 0.3 \\
\hline
\end{tabular}

Table 4: TCLP test results for modified sludge.

\begin{tabular}{lllll}
\hline & S1 & Cement & Sludge & Limit value \\
\hline Fe mg/L & 0.029 & 0.245 & 0.181 & -- \\
As $\mu \mathrm{g} / \mathrm{L}$ & 14.58 & 23.66 & 100 & 300 \\
\hline
\end{tabular}

\subsection{Hydration product analysis}

As Figure 4 shows, the iron content of steel slag is $23.34 \% \mathrm{Fe}_{2} \mathrm{O}_{3}$, and the mineral composition shows that iron mainly exists in the form of $\mathrm{C}_{4} \mathrm{AF}, \mathrm{FeO}$, and $\mathrm{RO}$. The content of $\mathrm{C}_{2} \mathrm{~S}$ and $\mathrm{C}_{3} \mathrm{~S}$ in steel slag is less than that of conventional cement. Figure 5 shows that the early hydration products of steel slag paste (three days) are calcium hydroxide and C-S-H gel, but the hydration 
degree was not apparent. By contrast, the hydration degree of S1 in the early stage evidently increased, more $\mathrm{C}-\mathrm{S}-\mathrm{H}$ gel formed, and the ettringite/Fe-ettringite and the calcium iron aluminum oxide peaks appeared. The peaks of ettringite and $\mathrm{Fe}$-ettringite are highly similar and thus difficult to distinguish (the main peak of $\mathrm{Fe}-$ ettringite at $2 \theta=9.13$, whereas that of Al-ettringite at $2 \theta$ = 9.09) [24]. The modifier S1 contains abundant steel slag powder, which is composed of calcium aluminate and calcium aluminoferrite, which can generate ettringite and $\mathrm{Fe}$-ettringite. In the presence of gypsum, the XRD pattern analysis is difficult to distinguish accurately due to the complex type of hydration products of steel slag, and further analysis combining with SEM and SEM-EDS is required. The analysis of the paste hydration product is shown in Figure 6. The main products of the steel slag are the C-S-H gel and portlandite, which are more abundant at a latter age. The products of $\mathrm{S} 1$ are $\mathrm{AFm} / \mathrm{Fe}-\mathrm{AFm}$ and $\mathrm{C}-\mathrm{S}-\mathrm{H}$ gel. The peak of AFt/Fe-AFt weakened relative to that at an early age possibly because the hydration products of calcium aluminate and calcium aluminoferrite translate to AFM/Fe-AFM when fluorine gypsum is exhausted.

As seen in the SEM morphology analysis of modified agent paste in Figure 7, at early age, the main products of S1 include an abundant amount of gel, as well as few needle-shaped ettringite and six-square flake-shaped portlandite. Short rod-shaped ettringite/Fe-ettringite appeared during for one-day hydration, and the rods were slightly elongated after three days (Figure 7a,b); however, the resultant structure is not complete, and the degree of hydration is low compared to that of cement with the water-cement ratio (Figure 7a,b-g,h). Cement hydration for three days resulted in a large number of morphologically intact gels with ettringite (Figure 7g,h). With the increase in curing time, the hydration product of S1 gradually grew more intact. On the 14th day, a large number of needle bar clusters appeared at the growth center, and the hexagonal flake calcium hydroxide grew in the cluster (Figure 7c,d). On the 28th day, the rod-like structure disappears, and a large number of lamellar structures appeared (Figure 7e). Combining with XRD results, these findings show that $\mathrm{AFt} / \mathrm{Fe}-\mathrm{Aft}$ is converted to $\mathrm{AFM} / \mathrm{Fe}-\mathrm{AFm}$ (Figure 6 and Figure 7e.). After hydration for 90 days, the structure of the $\mathrm{S} 1$ product became dense (Figure 7f).

The SEM image (Figure 8) of solidified shows that, in the case of sludge which filled with complex organic matter, the hydration of conventional cement was inhibited, whereas S1 hydration could continue. Thus, shear strength test exhibits an advantage of S1 in curing. In the early age, the main hydration products of

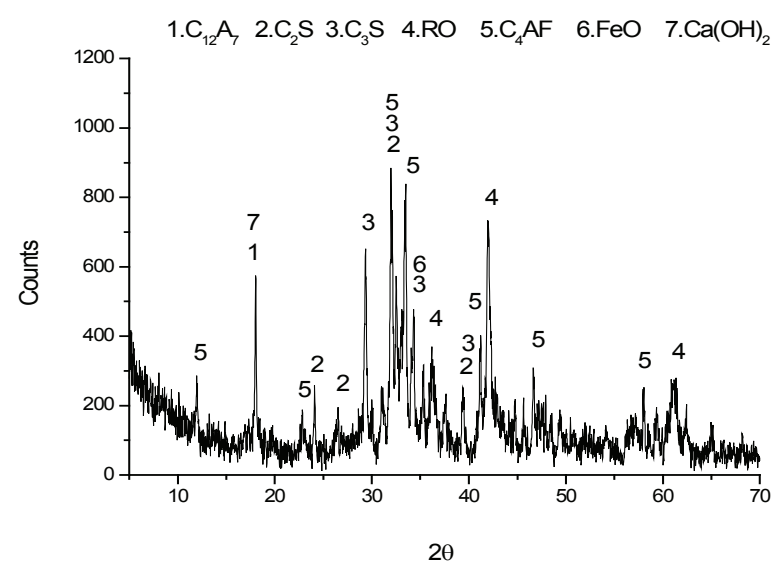

Figure 4: XRD analysis of steel slag powder.

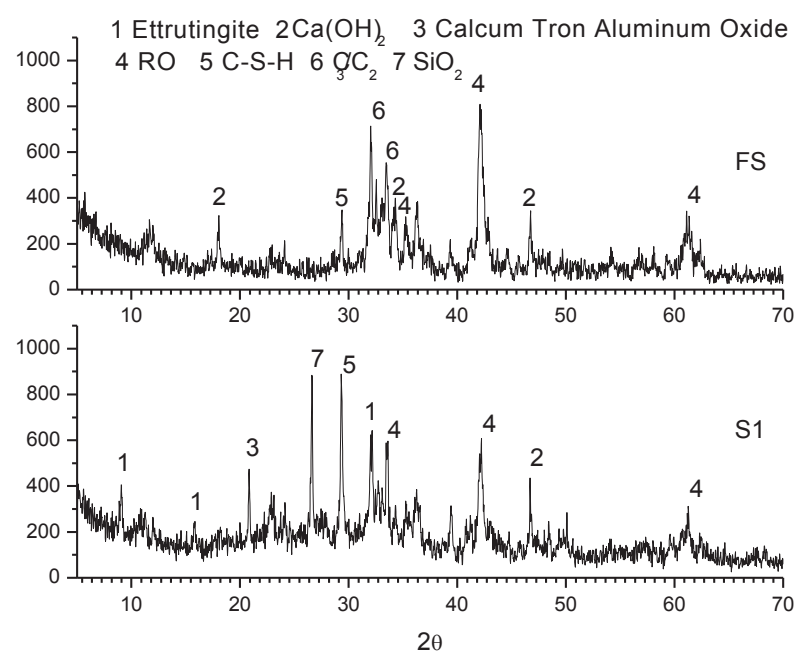

Figure 5: XRD analysis of $\mathrm{S} 1$ hydration products at 3 days (FS is original steel slag powder).

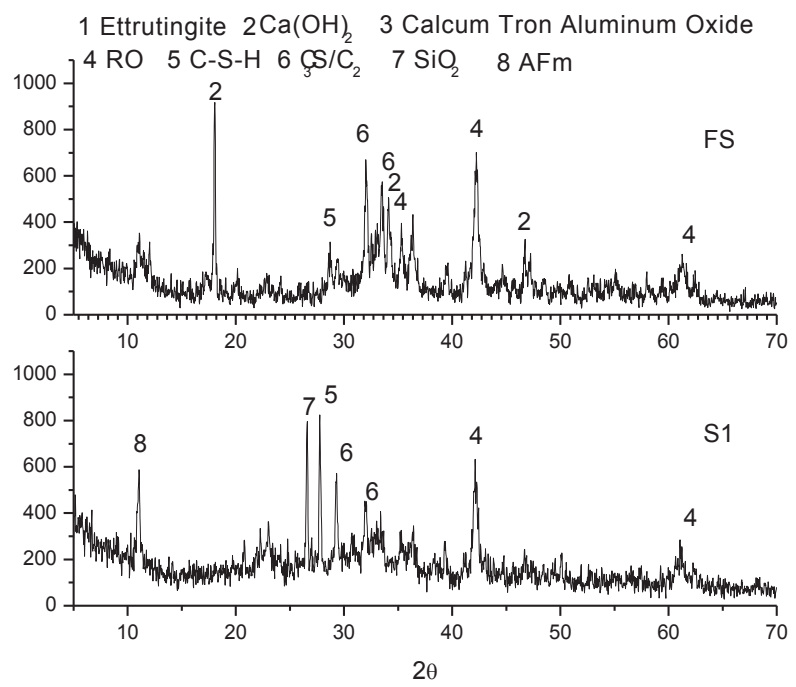

Figure 6: XRD analysis of $\mathrm{S} 1$ hydration products at 28 days (FS is original steel slag powder). 


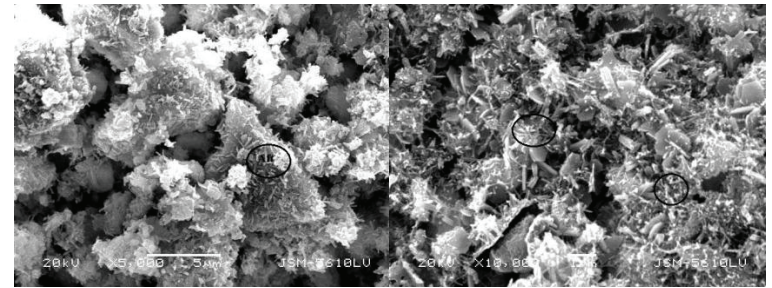

(a) S1 1day

(b) S1 3days

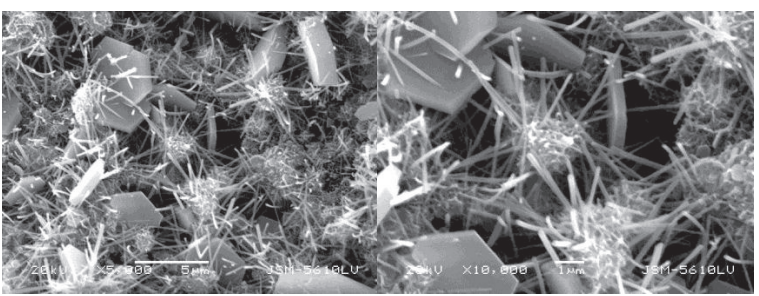

(c) S1 14 days

(d) S1 14 days

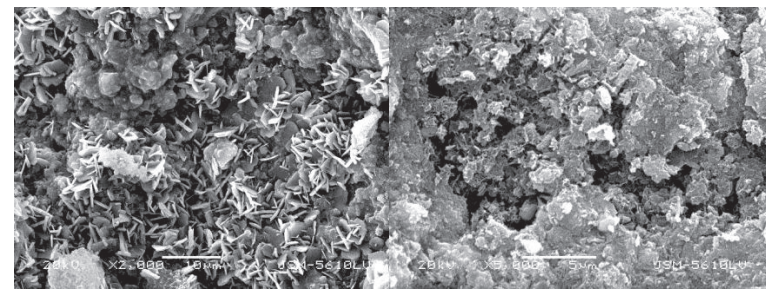

(e) S1 28 days

(f) S1 90 days

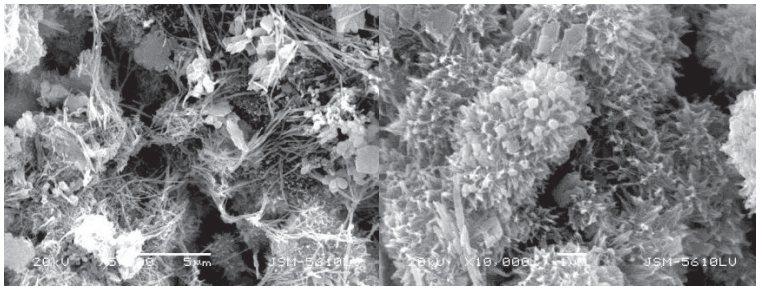

(g) Cement 3 days

(h) Cement 3 days

Figure 7: SEM analysis of paste hydration products (a-f: SEM of S1 paste curing for 1, 3, 14, 28, 90 days; g-h:SEM of cement paste curing at 3 days).

S1 solidified sludge are ettringite/Fe-ettringite. In terms of quantity, it has the phenomenon that the growth of the products showed an absolute advantage compared with the gel and calcium hydroxide stones (as opposed to the proportion of its paste product), and the products showed more slender and complete trend morphology compared to its paste product. The phenomenon may form because of the SEM pretreatment, in which the slurry and solidified sludge are immersed in the alcohol solution in the conventional manner and then dried at low temperature. However, the pore structure in the solidified sludge is more complex than that of the pure slurry sample. The degree of infiltration may present differences, which may lead to the incompletely terminated hydration

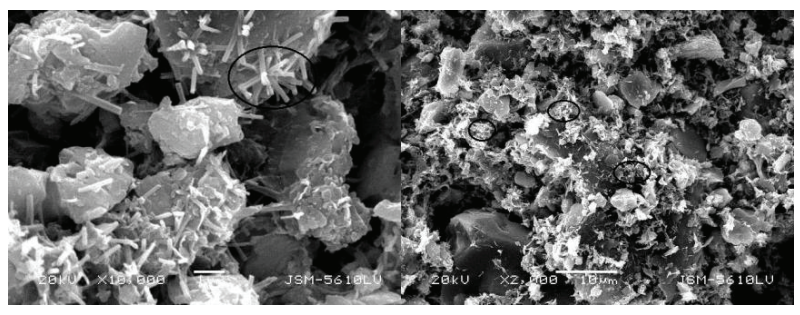

(a) Cement 3days

(b) Cement 3days

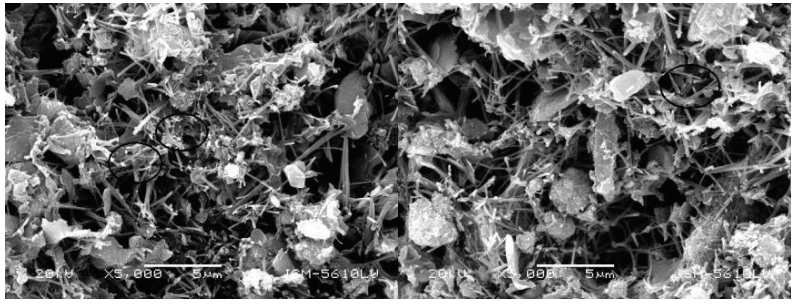

(c) S1 3days

(d) S1 14days

Figure 8: SEM analysis of hydration products in solidified sludge (a-b: SEM of cement solidified sludge curing for 3 days; $c-d$ : SEM of S1 solidified sludge curing at 3 days).

reaction of the net bubble process, resulting in a certain age difference between the two aquatic products. Thus, whether the organic matter in the sludge promotes the S1 hydration reaction needs further experimental proof. As observed in cement solidified sludge, the hydration was markedly inhibited compared with the cement paste or S1 solidified sludge, the quantity of the needlestate ettringite decreased, and the growth defect became shorter. According to the literature, a large amount of organic matter in the sludge inhibits cement hydration [25]. However, aluminide $12 \mathrm{CaO} \cdot 7 \mathrm{Al}_{2} \mathrm{O}_{3}$ can enhance the effect of cement-solidified sludge because the combination of aluminide makes the needle-shaped ettringite content increased, and ettringite formation can isolate the sludge particles, thereby reducing the inhibitory effect of organic sludge on cement hydration [11].

The needle-like structure mineral formed a uniform cross sludge organism similar as ettringite, which is a major hydration by-product of tricalcium aluminate in the presence of sulfate ions as formulated by Equation (1). The ettringite/Fe-ettringite morphology closely approximates the SEM results are difficult to differentiate. Therefore, the energy spectrum analysis was used to distinguish the results [24], the morphology of the S1/sludge need being further analyzed. Dense regions of ettringite/Fe-ettringite was spied among $\mathrm{S} 1$ hydrated products after being mixtures for one day as Figure 9a shows, then, discriminated by point scanning function of SEM-EDS as Figure 9b shows. However, as the EDS (Figure 9c) test shows, a large amount 


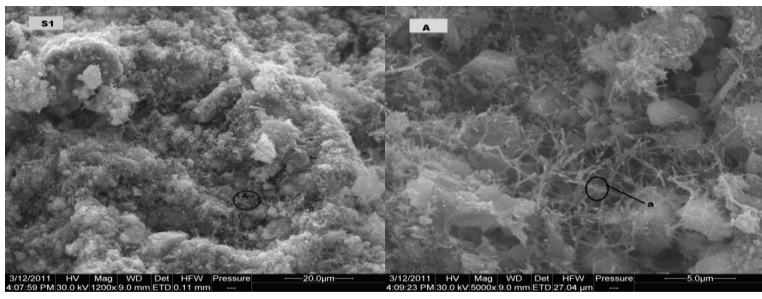

(a)

(b)

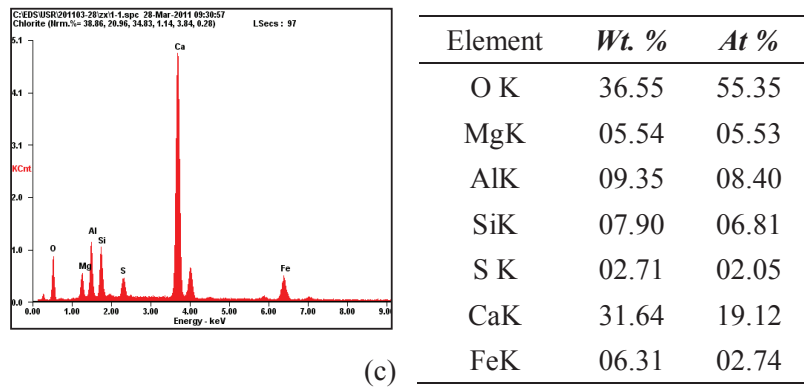

Figure 9: SEM- energy spectrum of S1 hydration products in sludge.

of Fe elements exist in this kind of mineral relative to ettringite, the mineral is more similar to iron-substituted $\mathrm{AFt}$, a hydration by-product of $\mathrm{C}_{4} \mathrm{AF}$, which is a solidsolution series called the ferrite phase, in the presence of sulfate ions as formulated by Equation (2). Ettringite formation reportedly reaches equilibrium after several days, whereas the balance of iron ettringite formation requires six months. By comparison, ettringite is formed from $\mathrm{CaO}, \mathrm{Fe}_{2}\left(\mathrm{SO}_{4}\right)_{3} \cdot 5.3 \mathrm{H}_{2} \mathrm{O}$, and/or $\mathrm{Al}_{2}\left(\mathrm{SO}_{4}\right)_{3} \cdot 16.2 \mathrm{H}_{2} \mathrm{O}$ to $0.032 \mathrm{KOH}$ solution [15], which deviates from the result of Equation (2). We think that the product is Fe-ettringite.

$$
\begin{aligned}
& \mathbf{3 C a O} \cdot \mathbf{A l}_{2} \mathbf{O}_{3}+\mathbf{3 C a S O}_{4}+32 \mathbf{H}_{2} \mathbf{O} \leftrightarrow \mathbf{C a}_{6} \mathbf{A l}_{2}\left(\mathbf{S O}_{4}\right)_{3}(\mathbf{O H})_{12} \cdot \mathbf{2 6} \mathbf{H}_{2} \mathbf{O} \\
& 3 \mathrm{C}_{4} \mathrm{AF}+60 \mathrm{H} \rightarrow 2 \mathrm{C}_{4}(\mathrm{~A}, \mathrm{~F}) \mathrm{H}_{19}+2 \mathrm{C}_{2}(\mathrm{~A}, \mathrm{~F}) \mathrm{H}_{8}+4(\mathrm{~F}, \mathrm{~A}) \mathrm{H}_{3} \\
& \rightarrow 4 \mathrm{C}_{3}(\mathrm{~A}, \mathrm{~F}) \mathrm{H}_{6}+2(\mathrm{~F}, \mathrm{~A}) \mathrm{H}_{3}+24 \mathrm{H}
\end{aligned}
$$

\section{Conclusions}

When the Slag sludge-based curing agent ratio was S1 [(steel slag: Activator): fluoride gypsum $=(90 \%$ : $10 \%): 2.5 \%$, the sludge water content showed the most marked decrease; A 20\% addition of S1 with curing at $20+1^{\circ} \mathrm{C}$ for 7 days, have enhanced the physicochemical properties of S1 solidified sludge to the standard of landfill (GB/T 23485-2009). The moisture content was reduced to $30 \%$ or less, the compressive strength ran up to 74.5 $\mathrm{kPa}$, and the permeability coefficient achieved was 5.03 $\times 10^{-5}(\mathrm{~cm} / \mathrm{s})$. The TCLP was below the limit value, thus it can be used as a covering material for refuse landfill. The main hydration product of S1might be Fe-Aft and it was generated without inhibition by organic matter in the sludge even in early age.

Acknowledgements: Thisstudy was financiallysupported by the Humanities and Social Sciences Foundation of Ministry of Education of China (17YJCZH081) and Nature Science Foundation of Hubei Province (2018CFB722).

Conflict of interest: Authors state no conflict of interest.

\section{References}

[1] Barrera-Díaz C., Martínez-Barrera G., Gencel O., BernalMartínez L.A., Brostow W., Processed wastewater sludge for improvement of mechanical properties of concretes, J. Hazard. Mater., 2011, 192, 108-115.

[2] Mohammad M.J., Athamneh B.M., Changes in soil fertility and plant uptake of nutrients and heavy metals in response to sewage sludge application to calcareous soils, J. Agron., 2004, 3, 229-236.

[3] Li F., Qiu Z., Zhang J., Liu W., Liu C., Zeng G., Investigation, pollution mapping and simulative leakage health risk assessment for heavy metals and metalloids in groundwater from a typical brownfield, middle china, Int. J. Env. Res. Pub. He., 2017, 14, 768.

[4] Sangiorgi C., Tataranni P., Mazzotta F., Simone A., Vignali V., Lantieri C., Alternative fillers for the production of bituminous mixtures: a screening investigation on waste powders, Coatings, 2017, 7, 76.

[5] Furness D.T., Hoggett L.A., Judd S.J., Therochemical treatment of sewage sluge, Water Environ. J., 2000, 14, 57-65.

[6] Kopp J., Dichtl N., Prediction of full-scale dewatering results by determining the water distribution of sewage sludge, Water Sci. Technol., 2000, 42, 141-149.

[7] Donatello S., Freeman-Pask A., Tyrer M., Cheeseman C.R., Effect of milling and acid washing on the pozzolanic activity of incinerator sewage sludge ash, Cement Concrete Comp., 2010, 32, 54-61.

[8] Kim E.H., Cho J.K., Yim S., Digested sewage sludge solidification by wastewater sludge for landing, Chemosphere, 2005, 59, 387-395.

[9] Zhen G., Yan X., Zhou H., Chen H., Zhao T., Zhao Y., Effects of calcined aluminum salts on the advanced dewatering and solidification/stabilization of sewage sludge, J. Environ. Sci., 2011, 23, 1225-1232.

[10] Zhang H., Yang J., Yu W., Luo S., Li P., Shen X., et al., Mechanism of red mud combined with Fenton's reagent in sewage sludge conditioning, Water Res., 2014, 59, 239-247.

[11] Shi Y., Yang J., Yu W., Zhang S., Liang S., Song J., et al., Synergetic conditioning of sewage sludge via $\mathrm{Fe}^{2+} /$ persulfate and skeleton builder: effect on sludge characteristics and dewaterability, Chem. Eng. J., 2015, 270, 572-581. 
[12] Valls S., Vazquez E., Stabilization and solidification of sewage sludge with Portland cement, Cement Concrete Res., 2000, 30, 1671-1678.

[13] Wang F., Wang H., Jin F., Al-Tabbaa A., The performance of blended conventional and novel binders in the in-situ stabilisation/solidification of a contaminated site soil. J. Hazard. Mater., 2015, 285,46-52

[14] Yang J.K., Shi Y.F., Yang X., Liang M., Li Y., Li Y.L., et al., Durability of autoclaved construction materials of sewage sludge-cement-fly ash-furnace slag. Constr. Build. Mater., 2013,48,398-405

[15] Minocha A.K., Jain N., Verma C.L., Effect of organic materials on the solidification of heavy metal sludge. Constr. Build. Mater., 2003, 17, 77-81.

[16] Fan Z.P., Zhu W., Zhang C.L., Experimental study on influence of organic matter content on solidified dredging, Rock Soil Mech., 2005, 26, 1326-1327. (in Chinese)

[17] Zhu W., Zeng K.L., Zhang C.L., Influence of organic matter component on solidification of dredged sediment, Rock Soil Mech., 2008, 29, 33-36. (in Chinese)

[18] Zhen G., Lu X., Cheng X., Chen H., Yan X., Zhao Y., Hydration process of the aluminate $12 \mathrm{CaO}-7 \mathrm{Al}_{2} \mathrm{O}_{3}$ assisted Portland cement-based solidification/stabilization of sewage sludge, Constr. Build. Mater., 2012, 30, 675-681.

[19] Zhu X., Hou H., Huang X., Zhou M., Wang W., Enhance hydration properties of steel slag using grinding aids by mechanochemical effect, Constr. Build. Mater., 2012, 29, 476 481.
[20] Wang Q., Li M., Shi M., Hydration Properties of Cement-Steel Slag- Ground Granulated Blast Furnace Slag Complex Binder, J. Chinese Ceram. Soc., 2014, 42, 629-634. (in Chinese)

[21] Huang J., Li F., Zeng G., Liu W., Huang X., Xiao Z., et al, Integrating hierarchical bioavailability and population distribution into potential eco-risk assessment of heavy metals in road dust: A case study in Xiandao District, Changsha city, China, Sci. Total Environ., 2016, 541, 969-976.

[22] Pomies M.P., Lequeux N., Boch P., Speciation of cadmium in cement Part 国. $\mathrm{Cd}^{2+}$ uptake by C-S-H, Cement Concrete Res., 2001, 31, 563-569.

[23] Zhou X., Zhou M., Wu X., Han Y., Geng J., Wang T., et al., Reductive solidification/stabilization of chromate in municipal solid waste incineration fly ash by ascorbic acid and blast furnace slag, Chemosphere, 2017, 182, 76-84.

[24] Möschner G., Lothenbach B., Winnefeld F., Ulrich A., Figi R., Kretzschmar R., Solid solution between Al-ettringite and Fe-ettringite $\left(\mathrm{Ca}_{6}\left[\mathrm{Al}-\mathrm{xFe} \mathrm{e}_{\mathrm{x}}(\mathrm{OH})_{6}\right]_{2}\left(\mathrm{SO}_{4}\right)_{3} \cdot 26 \mathrm{H}_{2} \mathrm{O}\right)$, Cement Concrete Res., 2009, 39, 482-489.

[25] Möschner G., Lothenbach B., Rose J., Ulrich A., Figi R., Kretzschmar R., Solubility of Fe-ettringite $\left(\mathrm{Ca}_{6}\left[\mathrm{Fe}(\mathrm{OH})_{6}\right]_{2}\left(\mathrm{SO}_{4}\right)_{3}\right.$ $\left.\cdot 26 \mathrm{H}_{2} \mathrm{O}\right)$, Geochim. Cosmochim. Ac., 2008, 72, 1-18. 